\title{
CARACTERIZAÇÃO DAS LESÕES ESPORTIVAS EM ATLETAS DE PARABADMINTON
}

\author{
Aline Miranda Strapasson, Universidade Estadual de Campinas - UNICAMP, Campinas, \\ São Paulo - Brasil \\ Dcheimy Janayna Baessa, Universidade Paranaense - UNIPAR, Todelo, Paraná - Brasil \\ Jalusa Andréia Strorch, Universidade Estadual de Campinas - UNICAMP, Campinas, São \\ Paulo - Brasil \\ Edison Duarte, Universidade Estadual de Campinas - UNICAMP, Campinas, São Paulo - \\ Brasil
}

\section{RESUMO}

O objetivo deste estudo foi caracterizar a prevalência de lesões esportivas em atletas com deficiência física que praticam Parabadminton (Pbd). Para tanto, realizou-se uma pesquisa de campo descritiva, exploratória, de natureza quantitativa e de corte transversal. A amostra foi composta por 19 atletas que participaram do Campeonato Nacional de Pbd. Como instrumento de coleta utilizou-se um questionário composto por 14 questões abertas e fechadas que trataram sobre particularidades da condição de deficiência, tempo de participação na modalidade e outros esportes, questões relativas as lesões esportivas nos atletas. Os resultados prevalentes relacionados as lesões esportivas foram: subluxação de ombro (13,35\%), entorse de tornozelo (13,35\%), escoriações de cotovelo e joelho (13,35\%), e com 6,66\%: bursite no ombro, epicondilite, cisto no punho, distensão muscular do bíceps braquial, contusão na costela, tendinite de membro inferior, ruptura do ligamento cruzado anterior do joelho, ruptura de menisco e fasceíte plantar. Em relação aos segmentos corporais afetados, constatou-se a prevalência de $47 \%$ das lesões afetando os membros superiores, $47 \%$ os membros inferiores e $6 \%$ o tronco. Inferiu-se que o Pbd gera risco para desenvolvimento de lesões esportivas em seus atletas, o que alerta-nos para a necessidade de implementação de medidas de prevenção e controle das mesmas.

Palavras-Chave: Parabadminton; Esporte adaptado; Lesões esportivas; Pessoa com deficiência física.

\section{CHARACTERIZATION OF SPORTS INJURIES IN PARA- BADMINTON ATHLETES}

\begin{abstract}
The purpose of this study was to characterize the sports injuries prevalence in physical disabilities athletes who practice Parabadminton (Pbd). Therefore, it was conducted a descriptive, exploratory, quantitative and cross-sectional field survey. The sample consisted of 19 athletes who participated in Brazilian Pbd Championship. For data collection was used a questionnaire consisting of 14 open and closed questions about disability condition, how long practiced $\mathrm{Pbd}$ and another sport, and questions that aimed to characterize the prevalence of sports injuries in athletes. The results of sports injuries were: shoulder subluxation (13.35\%), ankle sprain (13,35\%), elbow and knee bruises (13.35\%), and 6.66\%: shoulder Conexões: revista da Faculdade de Educação Física da UNICAMP, Campinas, v. 11, n. 4, p. 58-712, out./dez. 2013 ISSN: $1983-9030$


bursitis, tennis elbow, wrist cyst, brachial biceps muscle strain, rib injury, lower limb tendonitis, anterior cruciate ligament rupture of the knee, meniscus rupture and plantar fasciitis. In relation to body segments affected found a prevalence of $47 \%$ in upper limbs lesions, $47 \%$ in lower limbs and $6 \%$ in the trunk. The conclusion is that the Pbd can cause sports injuries in athletes, which alert us to implement measures to prevent and control them.

Key-Words: Parabadminton; Adapted sport; Athletic injuries; Physical disabilities.

\section{CARACTERIZACIÓN DE LESIONES DEPORTIVAS EN ATLETAS DE PARA-BADMINTON}

\section{RESUMEN}

El objetivo del estudio fue caracterizar la prevalencia de las lesiones deportivas en atletas con discapacidades físicas que practican Parabadminton (Pbd). Se realizó un estudio de campo descriptivo, exploratorio, cuantitativo y transversal. La muestra fue compuesta por 19 atletas que participaron del Campeonato Brasileño de Pbd. Fue utilizado un cuestionario con 14 preguntas abiertas y cerradas que trataban acerca de la condición de discapacidad, la duración de la participación en el deporte y cuestiones sobre lesiones deportivas. Los resultados fueron: subluxación de hombro $(13,35 \%)$, esguince de tobillo $(13,35 \%)$, hematomas en el codo y en la rodilla (13,35\%), y con 6.66\%: bursitis en el hombro, codo de tenista, quiste en la muñeca, la tensión del músculo bíceps braquial, lesión en las costillas, tendinitis en las extremidades inferiores, ruptura del ligamento cruzado anterior de la rodilla, ruptura del menisco y fascitis plantar. En relación a los segmentos del cuerpo afectados, fue visto una prevalencia de $47 \%$ de las lesiones en los miembros superiores, $47 \%$ en los miembros inferiores y $6 \%$ en el tronco. Llegamos a la conclusión que el Pbd crea un riesgo para el desarrollo de lesiones deportivas, siendo importante aplicar medidas para prevenir y luchar contra

lesiones.

Palabras-Clave: Parabadminton; Deportes adaptados; Lesiones deportivas; Personas con discapacidades físicas. 


\section{INTRODUÇÃO}

O esporte para pessoas com deficiência, engajado no movimento de "esporte adaptado" contempla várias modalidades, dentre elas o Badminton para pessoas com deficiência, ou Parabadminton (Pbd). ${ }^{1}$

O Pbd foi reconhecido em 1996 pelos fundadores da Associação Internacional de Badminton para deficientes, com o intuito de oportunizar a prática esportiva às pessoas com deficiência (física, intelectual e auditiva). ${ }^{2}$ Atualmente, existem 43 países filiados à referida associação, tendo como principais objetivos a difusão do esporte pelo mundo e a inserção da modalidade no movimento Paralímpico de 2020, remetendo-se apenas a participação de pessoas com deficiência física. ${ }^{3}$

No Brasil, o esporte foi idealizado por um professor de Educação Física de Brasília-DF ${ }^{4}$ e constata-se que o Parabadminton está sendo praticado em 13 estados brasileiros. ${ }^{5}$

De acordo com a Federação Mundial de Badminton ${ }^{\mathrm{i}}$, as principais adaptações do esporte estão relacionadas: às categorias, nivelando os atletas de acordo com sua deficiência; à quadra (diminuição da área de jogo quando necessário); e equipamentos adicionais (cadeira de rodas específica para a modalidade, muletas e próteses). ${ }^{6}$

O Pbd oferece seis categorias, sendo duas para pessoas que utilizam cadeiras de rodas e quatro para pessoas que não necessitam do uso de cadeira de rodas. ${ }^{6}$

As classes para usuários de cadeira de rodas são divididas em WH1 e WH2 (W de wheelchair); e as classes dos não usuários de cadeira de rodas são divididas em SL3, SL4, SU5 e SS6 (S de standing). ${ }^{6}$

Na classe WH1 participam usuários de cadeira de rodas com equilíbrio corporal moderado ou ruim, enquanto a classe WH2 contemplam usuários de cadeira de rodas com bom equilíbrio corporal. Nas classes SL3 e SL4 participam atletas com comprometimento dos membros inferiores; na SU5 atletas com comprometimento de membros superiores, e na classe SS6

\footnotetext{
i Badminton World Federation: http://www.bwfbadminton.org/ Conexões: revista da Faculdade de Educação Física da UNICAMP, Campinas, v. 11, n. 4, p. 58-712, out./dez. 2013 ISSN: $1983-9030$
} 
participam atletas com baixa estatura (acondroplasia ou nanismo, sendo masculino até $145 \mathrm{~cm}$ e feminino até $137 \mathrm{~cm})^{6}$

O sistema de jogo é similar ao Badminton, disputado em uma quadra coberta retangular, com 13,40 metros de comprimento por 6,10 metros de largura (tamanho da quadra sem adaptação para as classes SL4, SU5 e SS6), dividido por uma rede de 1,55 metros de altura. Cada jogador tem posse de uma raquete e o objetivo do jogo é rebater, por cima da rede, uma pequena peteca. Aquele que deixar a peteca cair dentro do seu lado da quadra ou rebater a peteca para fora da quadra perde a jogada. ${ }^{7-11}$

Cada partida é disputada em até três games de 21 pontos. Em caso de empate em 20 a 20, o jogo é prolongado para 22 pontos. Caso empate em 21 a 21, é prolongado para 23 pontos e assim até os 30 pontos máximos. Quem vencer primeiro dois games ganha a partida. $^{7-11}$

O Badminton e o Pbd são jogados nas modalidades simples masculina, simples feminina, dupla masculina, dupla feminina e dupla mista. ${ }^{10-11}$

Verifica-se na atualidade que o esporte vem ganhando adeptos ao longo dos anos, os quais buscam melhor rendimento e desempenho na atividade. Contudo, assim como em qualquer esporte de rendimento, os atletas buscam melhor nível técnico e altos índices por meio da intensificação dos treinamentos/competições, o que pode acarretar diversas lesões esportivas no aparelho osteomuscular.

Uma lesão pode significar uma redução no nível de treinamento e condicionamento diminuindo a motivação do atleta. A perda de tempo relacionada a traumas e doenças afeta negativamente a qualidade do processo da preparação, levando à desadaptação do organismo. $^{12}$

Partindo do problema de que os atletas do Pbd estariam pré-dispostos a desenvolverem lesões esportivas no sistema osteomuscular, devido à necessidade de alta eficiência no gesto esportivo, o presente estudo respalda-se no intuito de caracterizar as lesões esportivas mais 
prevalentes nos atletas com deficiência física participantes da modalidade, em situações de competição esportiva.

\section{MÉTODOS}

O tipo de estudo realizado foi uma pesquisa de campo descritiva, exploratória, de natureza quantitativa e de corte transversal. ${ }^{13}$ Este trabalho foi aprovado em 18/09/2012 pelo Comitê de Ética envolvendo seres humanos da Universidade Paranaense (CAAE: 05346812.4.0000.0109).

Participaram deste trabalho 19 atletas de ambos os gêneros (95\% masculino e 5\% feminino), com média de idade de 26,7 anos $( \pm 11,6)$, representando os estados do Rio de Janeiro (5\%), de São Paulo (21\%), do Paraná (32\%) e Distrito Federal (42\%). Estes competiram na $2^{\text {a }}$ Etapa do Campeonato Nacional de Parabadminton, realizado na cidade de Campinas-SP, no ano de 2012. Os critérios de inclusão foram atletas participantes da modalidade há mais de um ano, que realizam treinamentos semanais regularmente.

Para a coleta de dados utilizou-se um questionário elaborado pelos pesquisadores, composto por 14 questões abertas e fechadas que trataram sobre particularidades da condição de deficiência física, tempo de participação no Pbd e em outras modalidades esportivas, além de questões que buscaram caracterizar a prevalência de lesões esportivas nos atletas. Convém ressaltar que, previamente foi realizado um estudo piloto para adequar o instrumento.

Inicialmente foi entregue o termo de consentimento da pesquisa, e mediante o aceite, foi aplicado um roteiro de entrevista semiestruturado. Destaca-se que a coleta transcorreu em momentos de repouso dos atletas durante as competições, visando não atrapalhá-los no rendimento de suas atividades esportivas. Posteriormente, os dados obtidos foram tabulados e categorizados por meio da estatística descritiva, compreendendo a frequência absoluta e relativa, além de medidas de média e desvio padrão, os quais serão explanados no próximo tópico.

\section{RESULTADOS}


A seguir serão apresentados os dados expostos em frequência absoluta e relativa, seguindo a ordem das questões contidas no instrumento de coleta de dados:

\section{Quanto à caracterização da deficiência física dos participantes:}

Seguindo a ordem dos questionamentos, verificou-se que os atletas com deficiência física, de origem congênita ou adquirida, apresentam a seguinte etiologia (Tabela 1):

Tabela 1 - Etiologia das deficiências físicas dos participantes.

\begin{tabular}{llc}
\hline Etiologia & F & \% \\
\hline Lesão medular & 7 & 38 \\
Amputação & 3 & 16 \\
Lesão do plexo braquial & 2 & 10 \\
Mielomeningocele & 1 & 5 \\
Paralisia Cerebral & 1 & 5 \\
Polineuropatia & 1 & 5 \\
Poliomielite & 1 & 5 \\
Outras causas & 3 & 16 \\
\hline
\end{tabular}

Fonte: dados dos pesquisadores (2012)

Dentre as causas apontadas para as deficiências físicas, constatou-se que 58\% (11 atletas) foram por acidentes diversos (automobilístico e arma de fogo), 16\% (03 atletas) infecção viral, 11\% (02 atletas) malformação congênita, 5\% (01 atleta) anóxia perinatal, 5\% (01 atleta) acidente vascular encefálico, 5\% (01 atleta) Síndrome de Tonni Deebri de Faconni.

\section{Quanto à categoria dos atletas na modalidade do Parabadminton}

Dentre as categorias dos participantes na modalidade do Pbd, averiguou-se que $58 \%$ da amostra (11 pessoas) compreende a classe Wheelchair (usuários de cadeira de rodas), 26\% (05 pessoas) a classe Standing - SL3 e SL4 (andantes com comprometimento de membros inferiores) e 16\% (03 pessoas) da classe Standing - SU5 (andantes com comprometimento de membros superiores). Nenhum dos atletas faz parte da categoria SS6, baixa estatura nanismo.

Em relação ao tempo médio de prática do Pbd, apontou-se para 30,7 meses $( \pm 20,5)$. Quanto à frequência de participação dos atletas nos treinos de Parabadminton, revelou-se 2,52 vezes por semana $( \pm 0,90)$, com duração média de $2 \mathrm{~h} 13^{\prime}( \pm 0,62)$. 


\section{Quanto à participação dos atletas em outras modalidades esportivas}

Dos 19 participantes questionados, 68\% mencionaram praticar outra(s) modalidade(s) além do $\mathrm{Pdb}$ e $32 \%$ revelaram não praticar nenhum outro esporte. Dentre as modalidades praticadas, constatou-se o tênis de campo (05 pessoas), o tênis de mesa (4), o handebol em cadeira de rodas (4), a natação (3), o atletismo (1), a capoeira (1), o frescobol (1) e o tiro com $\operatorname{arco}(1)$.

\section{Em relação à prevalência de lesões esportivas dentre os atletas do Parabadminton}

Quando questionados sobre a presença de lesões esportivas ortopédicas advindas da prática do Pbd 79\% (15 atletas) comentaram sofrer lesões e 21\% alegaram (4) que não sofreram nenhuma lesão até o momento da pesquisa.

Dentre as 15 lesões esportivas citadas, constatou-se que 54\% (8) ocorreram em momentos de competição, 33\% (5) das lesões em momentos de treinamento e 13\% (2) em ambos (competição e treino).

Em relação à presença de diagnóstico clínico, assegurado por médico e/ou exame de imagem, $54 \%$ (8) descreveram que as lesões foram diagnosticadas clinicamente e 46\% (7) citaram que não houve diagnóstico. Quanto à recuperação das lesões esportivas, verificou-se que 80\% (12) apresentaram recuperação completa e $20 \%$ (3) recuperação parcial.

Por meio do instrumento de coleta de dados, constatou-se 13 diferentes tipos de lesões esportivas, dentre os comprometimentos articulares, ligamentares, tendíneos e musculares, apresentadas na Tabela 2: 
Tabela 2 - Prevalência das lesões esportivas citadas pelos participantes do estudo

\begin{tabular}{lcc}
\hline Etiologia & F & \% \\
\hline Escoriação de cotovelo e joelho & 2 & 13,35 \\
Tendinite de membro inferior & 1 & 6,66 \\
Subluxação de ombro & 1 & 6,66 \\
Entorse de tornozelo & 1 & 6,66 \\
Bolhas na mão e joelho & 1 & 6,66 \\
Bursite no ombro & 2 & 13,35 \\
Epicondilite & 1 & 6,66 \\
Cisto no punho & 1 & 6,66 \\
Distensão muscular do bíceps braquial & 1 & 6,66 \\
Contusão na costela & 1 & 6,66 \\
Rompimento do ligamento cruzado anterior do joelho & 1 & 6,66 \\
Ruptura de menisco & 1 & 6,66 \\
Fasceíte plantar & 1 & 6,66 \\
\hline
\end{tabular}

Fonte: Dados dos pesquisadores (2012)

Averiguou-se que 15 participantes apresentaram uma ou mais lesões esportivas, sendo as lesões mais prevalentes - escoriação de cotovelo/joelho $(13,35 \%)$ e bursite no ombro $(13,35 \%)$. Quanto aos segmentos corporais afetados, constatou-se que 47\% atingiram membros superiores, $47 \%$ membros inferiores e $6 \%$ o tronco, com maior prevalência para lesões de grau leve.

Em relação à recuperação das referidas lesões, 80\% (12 atletas) citaram recuperação completa e $20 \%$ (3) recuperação parcial.

Quando questionados sobre os tratamentos realizados para reparo das lesões, evidenciou-se que $73 \%$ (11) dos participantes fizeram uso de gelo (crioterapia), 73\% (11) utilizaram pomada anti-inflamatória, 46\% (07) administraram uso de anti-inflamatório oral, 33\% (05) realizaram fisioterapia, 33\% (05) permaneceram em repouso, 13\% (02) necessitaram permanecer imobilizados, $06 \%$ (1) realizou procedimento cirúrgico e 06\% (01) executou trabalho de fortalecimento muscular em serviços de academia.

O tempo médio de recuperação das lesões adquiridas foi de 13,63 dias $( \pm 23,69)$.

\section{DISCUSSÃO}

Nessa pesquisa, evidenciou-se que a maior parte da amostra são usuários de cadeira de rodas, devido à lesão na medula espinhal e amputação de membros inferiores, os quais correspondem à classe esportiva Wheelchair. Dentre os 19 atletas entrevistados, 15 deles Conexões: revista da Faculdade de Educação Física da UNICAMP, Campinas, v. 11, n. 4, p. 58-712, out./dez. 2013 
apresentam ou já apresentaram lesões esportivas decorrentes da prática esportiva do Parabadminton, advindas de treinamento, competição ou ambos.

Percebe-se que a prevalência de lesões esportivas nestes atletas é elevada, cujos fatores de risco estão atrelados a condição de deficiência física, tanto pela demanda das atividades de vida diária, como também pelas altas exigências esportivas.

A literatura enfatiza que o risco de lesões esportivas em atletas de rendimento com deficiência física ${ }^{14}$ é semelhante ao risco para atletas sem deficiência, devido ao esporte adaptado ter atingido o profissionalismo. Com a busca do alto rendimento e grandes desempenhos os atletas são submetidos a esforços físicos muito próximos dos seus limites fisiológicos, tornando-se uma faixa de atividade física potencialmente patológica que resulta em debilidades no aparelho locomotor. ${ }^{14-15}$

Nesta população, as lesões têm uma particularidade: a soma da biomecânica do esporte com a deficiência, ${ }^{14-15}$ principalmente nos casos de deficiência física, devido ao uso excessivo das funções remanescentes dos membros superiores, como: a intensa movimentação da cadeira de rodas e transferências, seja no esporte, como nas atividades de vida diária. As lesões apresentam características particulares decorrentes destes fatores, mais comumente designadas como lesões por overuse (excesso). ${ }^{15}$

Quanto ao sistema de classificação, as lesões podem ser classificadas em dois principais grupos: acidentes esportivos e lesões por sobrecarga. ${ }^{16}$

Lesões por acidentes esportivos ocorrem de forma aguda durante competição ou treinamento, sendo resultantes de um só impacto ou macrotrauma, as quais representam cerca de $10 \%$ dos casos. Como exemplos, apresentam-se: fraturas, estiramentos e luxações, tendo maior frequência nos esportes de contato e de combate. ${ }^{16}$

Já as lesões de sobrecarga são causadas por microtraumas de repetição, cargas físicas repetitivas e recuperação inadequada do sistema músculo-esquelético, convertendo-se em lesões crônicas, com fases de melhoras e recidivas, limitando o gesto esportivo e podendo 
levar ao afastamento do esporte. Estas correspondem a 90\% das lesões, sendo representadas por: tendinites, periostites, bursites, fraturas por fadiga ou estresse, lesões ligamentares. ${ }^{16}$

Devido à carência de pesquisas que tratam sobre a temática das lesões esportivas no Parabadminton, respaldamo-nos na literatura acerca do Badminton, visto que é um esporte base da modalidade e de semelhante exigência física, sobretudo para a articulação do ombro durante a realização dos movimentos de abdução e rotação externa frequentes. ${ }^{17}$

Neste contexto, um estudo investigou 188 atletas participantes de um Campeonato Mundial e verificou-se que $52 \%$ revelaram dores no ombro dominante, o que prejudicou os treinamentos e o desempenho nas competições. ${ }^{17}$ Outro estudo avaliou 124 atletas de Badminton do gênero masculino, com idade média de 23,8 anos, em que buscou-se avaliar as lesões de cotovelo. Destes, 17,7\% (22) dos atletas apresentaram epicondilite lateral do cotovelo e $9,7 \%$ (12) apresentaram epicondilite medial. ${ }^{18}$

Outro estudo investigou a prevalência de lesões do tendão do calcâneo de 66 atletas de elite de Badminton, sendo 41 homens (com idade média de 24,4 anos) e 25 mulheres (idade média de 21,9 anos). Os resultados apresentaram que 21 jogadores (32\%) tiveram ocorrência de dores incapacitantes no tendão calcâneo por cinco anos, ao passo que 11 jogadores (17\%) revelaram episódios agudos de dores. Como fator de risco foi apontado carga excessiva de treinamento. ${ }^{19}$

Já na Suécia, um estudo do Hospital Universitário da Universidade de Umea relatou 31 rupturas de tendão do calcâneo entre 1990 e 1994, resultantes da prática amadora do Badminton. Os pacientes tinham em média 36 anos de idade, sendo 27 homens e quatro mulheres. ${ }^{20}$ Outra investigação de Jørgensen e Winge ${ }^{21}$ sobre a epidemiologia das lesões do Badminton na temporada de competição de 1983/1984 perfez um registro de 257 lesões, sendo mais frequentes nos homens. As principais lesões detectadas foram distensões, entorses e fraturas. De semelhante modo, na presente pesquisa revelou-se uma distensão muscular $(6,66 \%)$, duas entorses $(13,35 \%)$, contudo, nenhuma fratura $(0 \%){ }^{21}$

Outra pesquisa transversal realizada na Dinamarca durante o período de um ano registrou lesões em 100 jogadores de Badminton, sendo 58\% do gênero masculino e $42 \%$ do gênero 
feminino. ${ }^{22}$ As lesões diagnosticadas foram entorses, ruptura do tendão do calcâneo, ruptura do tendão do tornozelo e fraturas. Esses atletas precisaram de um tempo superior a oito semanas para reabilitação. ${ }^{22}$

$\mathrm{Na}$ Malásia, pesquisadores da Clínica do Instituto Nacional de Esportes detectaram 469 lesões esportivas ocasionadas pelo Badminton, no período de janeiro de 2005 a junho de 2007. Verificou-se que 52,9\% das lesões ocorreram no gênero masculino. Das 469 lesões, $63,1 \%$ foram nos membros inferiores, $18,1 \%$ nos membros superiores, $16,6 \%$ nas costas, $1,7 \%$ no pescoço e $0,5 \%$ no abdômen. ${ }^{23}$

\section{CONCLUSÃO}

De acordo com os estudos prévios utilizados no levantamento bibliográfico, assim como os achados desta pesquisa, confirmaram que as modalidades pertencentes ao esporte adaptado pré-dispõem ao risco de desenvolvimento de lesões esportivas em seus atletas, sobretudo, quando o esporte apresenta o caráter de rendimento, devido ao intenso e crescente aperfeiçoamento das capacidades físicas, técnicas, táticas e psicológicas, tanto nos treinamentos, quanto nas competições esportivas.

Esta pesquisa evidenciou que a incidência de lesões esportivas em atletas com deficiência física foi considerada como alta, visto que dentre 19 participantes, 15 relataram apresentar uma ou mais lesões esportivas ao longo de treinamentos e/ou competições de Parabadminton, tendo em média 13,63 dias para se recuperarem.

Por sua vez, as lesões mais prevalentes foram escoriação de cotovelo e joelho (2 atletas), além de bursite no ombro (2 atletas), perfazendo 13,35\% cada. Quanto aos segmentos mais acometidos, $47 \%$ das lesões afetaram os membros superiores, $47 \%$ os membros inferiores e $6 \%$ o tronco. Ou seja, a predominância de lesões entre os segmentos corporais superiores e inferiores é semelhante, pelo fato da demanda esportiva exigir movimentos repetitivos para ataque e defesa com a raquete, além da intensa necessidade de deslocamento em quadra. Também foi constatado que 54\% (8) das lesões ocorreram em momentos de competição, $33 \%$ (5) em momentos de treinamento e 13\% (2) em ambos (competição e treino). 
Acredita-se que tal fato esteja associado às condições musculares dos atletas, ao baixo condicionamento físico inadequado, excesso de treinamento e ausência de programas de acompanhamento ou preventivos de lesões. Nestas circunstâncias, devido à existência de fatores predisponentes intrínsecos e extrínsecos, que variam de acordo com cada modalidade esportiva e, também, à ausência ou deficiência de programas de prevenção, geram-se comprometimentos de gravidade leve a severa no aparelho locomotor dos atletas.

Sugere-se como importante medida a estes atletas a necessidade da prevenção de lesões esportivas por meio de treinamentos físicos que otimizem o condicionamento físico dos atletas em geral (alongamento e fortalecimento muscular, treino proprioceptivo e condicionamento aeróbico), além de novos estudos referentes à área que possibilitem o desenvolvimento de metodologias para acompanhamento periódico (periodização dos treinamentos) e prevenção das lesões esportivas nesta modalidade, visto a carência de literatura científica em contexto nacional e internacional.

\section{REFERÊNCIAS}

${ }^{1}$ BWF - BADMINTON WORLD FEDERATION. Para-Badminton: overview. 2012. Disponível em: <http://www.bwfbadminton.org/page.aspx?id=15437>. Acesso em: 28 jun. 2012.

${ }^{2}$ DISABILITY SPORT WALE. Chwaraeon Anabledd Cymru. Community Cymuned. Badminton/Wheelchair Badminton. 2007. Disponível em: <http://www.disability-sportwales.org/10714.html> Acesso em: 05 maio 2010.

${ }^{3}$ BWF - BADMINTON WORLD FEDERATION. National Para-Badminton Contacts. 2013. Disponível em: <http://www.bwfbadminton.org/page.aspx?id=23018>. Acesso em: 10 out. 2013.

${ }^{4}$ FERNANDO, H. Badminton adaptado promete decolar em Brasília. 2010. Disponível em: <http://www.badminton.org.br/noticias695.asp> Acesso em: 05 mar. 2010. 
${ }^{5}$ SAMARONE, L. Entrevista concedida à Aline Miranda Strapasson. Campinas, 16 out. 2013.

${ }^{6}$ BWF - BADMINTON WORLD FEDERATION. BWF Para-Badminton classification cegulations. 2011 Disponível em: <www.bwfbadminton.org/file_download.aspx?id=66422\&tid=1>. Acesso em: 28 jun. 2012.

${ }^{7}$ DUARTE, O. História dos esportes. São Paulo: Makron Books do Brasil, 2000.

${ }^{8}$ DUARTE, O. História dos esportes. 4. ed. São Paulo: Ed. SENAC SP, 2003.

${ }^{9}$ ALMANAQUE ABRIL. Esporte. São Paulo: Abril, 2005.

${ }^{10}$ BWF - BADMINTON WORLD FEDERATION. Laws of Badminton (Parabadminton $\begin{array}{llll}\text { clauses } & \text { shaded). } & \text { Disponível }\end{array}$ <http://www.bwfbadminton.org/file_download.aspx?id=364295\&tid=1> Acesso em: 18 julho 2012.

${ }^{11}$ COMITÊ OLÍMPICO BRASILEIRO (COB). Badminton. Peteca olímpica. 2011. Disponível em: <http://www.cob.org.br/esportes/infograficos/BD/index.html> Acesso em 18 mar. 2011.

${ }^{12}$ FERRARA, M. S.; BUCKLEY, W. E. Athletes with disabilities injury registry. Adapted Physical Activity Quarterly, Champaign, v. 13, n. 1, p. 50-60, 1996.

${ }^{13}$ THOMAS, J. R.; NELSON, J. K.; SILVERMAN, S. J. Métodos de pesquisa em atividade física. 6. ed. Porto Alegre: Artmed, 2012.

${ }^{14}$ ROCCO, F. M.; SAITO, E. T. Epidemiologia das lesões esportivas em atletas de basquetebol em cadeira de rodas. Acta Fisiátrica, São Paulo, v. 13, n. 1, p. 17-20, 2006.

${ }^{15}$ GANTUS, M. C.; ASSUMPÇÃO, J. D. Epidemiologia das lesões do sistema locomotor dos atletas de basquetebol. Acta Fisiátrica, São Paulo, v. 9, n. 2, p. 77-84, 2002. 
${ }^{16}$ ANDRADE, C. C. A.; CASTRO, T. G. M. Epidemiologia das lesões traumatoortopédicas no esporte adaptado. 2010. 29f. Monografia (Graduação em Fisioterapia) Faculdade de Fisioterapia, Universidade Federal de Minas Gerais, Belo Horizonte, 2010.

${ }^{17}$ DANTAS, M. J. B.; SOUZA, T. L. F.; SILVEIRA, J. C.; SANTOS, R. R. L. Epidemiologia das lesões esportivas nos atletas da terceira divisão do campeonato brasileiro de basquetebol em cadeira de rodas. Extensão e Sociedade, v. 3, n. 3, 2011.

${ }^{18}$ AZARBAL, M.; ADYBEIK, D.; ETTEHAD, H.; KIA, M. A. A survey of elbow injuries in badminton players. Internet Journal of Orthopedic Surgery, Texas, v. 2, n. 1, jan. 2003.

${ }^{19}$ FAHLSTRÖM, M.; LORENTZON, M.; ALFREDSON, H. Painful conditions in the achilles tendon region in elite badminton players. American Journal of Sports Medicine, Chicago, v. 30, n. 1, p. 51-54, 2002.

${ }^{20}$ FAHLSTRÖM, M.; BJÖRNSTIG, U.; LORENTZON, R. Acute achilles tendon rupture in badminton players. American Journal of Sports Medicine, Chicago, v. 26, n. 3, p. 467-470, 1998.

${ }^{21}$ JØRGENSEN, U.; WINGE, S. Epidemiology of badminton injuries. Internacional Journal Sports Medicine, Sttugart, v. 8, n. 6, 1987.

${ }^{22} \mathrm{H} \varnothing \mathrm{Y}$, K. et al. Badminton Injuries: a prospective epidemiological and socioeconomic study. British Journal of Sports Medicine, London, v. 28, n. 4, p. 276-279, dez. 1994.

${ }^{23}$ SHARIFF, A. H.; GEORGE. J.; RAMLAN, A. A. Musculoskeletal injuries among malaysian badminton players. Singapure Medical Journal, Singapure, v. 50, n. 11, p. 10951097, 2009.

Recebido em: 12 ago. 2013 Aceito em: 19 nov. 2013

Contato: Edison Duarte Edison@fef.unicamp.br 